\title{
SISTEM PAKAR DIAGNOSA PENYAKIT BAWANG MERAH MENGGUNAKAN METODE FORWARD CHAINNING
}

\author{
(THE EXPERT SYSTEM FOR DIAGNOSING RED ONION USING FORWARD CHAINING) \\ Titi Supianti'), Ahmad Ashril Rizal' ${ }^{2}$, Lalu Puji Indra Kharisma ${ }^{3)}$, Khairunnazri' ${ }^{4}$ \\ ${ }^{1,2,3,4)}$ Program Studi Teknik Informatika STMIK Syaikh Zainuddin Nahdlatul Wathan \\ Jln. Raya Mataram - Lb Lombok KM 49 Desa Anjani Lombok Timur \\ e-mail: titisupianti04@gmail.com ${ }^{1)}$, ashril.rizal@gmail.com ${ }^{2}$, lalupujii@gmail.com ${ }^{3)}$, m4sterlenk@gmail.com ${ }^{3)}$
}

\begin{abstract}
ABSTRAK
Konsultasi terhadap seseorang yang memiliki expertise dibidang tertentu dalam menyelesaikan suatu permasalahan merupakan pilihan tepat guna mendapatkan jawaban, solusi, keputusan atau kesimpulan terbaik. Jawaban seorang expert atas sebuah konsultasi tentunya sangat dapat dipercaya atau dipertanggungjawabkan serta dapat berpengaruh terhadap mutu serta kualitas hasil dari suatu solusi permasalahan, ini dikarenakan seorang expert selalu menguasai terhadap bidang yang ditekuninya berdasarkan keilmuan dan pengalamannya.Demikian pula para petani tanaman bawang merah yang mengalami berbagai permasalahan atau berbagai faktor diantaranya adalah teknik budidaya, kondisi lingkungan serta gangguan hama dan penyakit. Namun dalam menentukan penyakit yang terdapat pada tanaman bawang merah ini masih menggunakan cara manual sehingga memerlukan proses yang lebih rumit dan memakan waktu yang cukup lama. sistem pakar adalah suatu sistem komputer yang menyamai (emulates) kemampuan pengambilan keputusan dari seorang pakar. Berdasarkan permasalahan tersebut, maka dirancang suatu aplikasi yang mampu menganalisa suatu penyakit pada tanaman bawang merah secara cepat dan tepat dengan judul "Sistem Pakar Diagnosa Penyakit Tanaman Bawang Merah Menggunakan Metode Forward Chainning”.
\end{abstract}

Kata Kunci: Sistem Pakar, Forward Chainning, Bawang Merah

\section{ABSTRACK}

Consulting someone who has expertise in a particular field in solving a problem is the right choice in order to get the best answer, solution, decision or conclusion. An expert's answer to a consultation is of course very trustworthy or accountable and can affect the quality and quality of the results of a solution to a problem, this is because an expert always masters the field he is engaged in based on his knowledge and experience.Likewise, shallot plant farmers who experience various problems or various factors including cultivation techniques, environmental conditions and pests and diseases. However, in determining the disease contained in this shallot plant, it is still using the manual method so it requires a more complicated and time-consuming process. An expert system is a computer system that emulates the decision-making ability of an expert. Based on these problems, an application that is able to analyze a disease in shallot plants is designed quickly and precisely with the title "Expert System for Diagnosis of Shallot Plant Diseases Using the Forward Chainning Method".

Keywords : Expert System, Forward Chainning, Shallot

\section{Pendahuluan}

$\mathrm{K}$ onsultasi terhadap seseorang yang memiliki expertise dibidang tertentu dalam menyelesaikan suatu permasalahan merupakan pilihan tepat guna mendapatkan jawaban, solusi, keputusan atau kesimpulan terbaik. Jawaban seorang expert atas sebuah konsultasi tentunya sangat dapat dipercaya atau dipertanggungjawabkan serta dapat berpengaruh terhadap mutu serta kualitas hasil dari suatu solusi permasalahan, ini dikarenakan seorang expert selalu menguasai terhadap bidang yang ditekuninya berdasarkan keilmuan dan pengalamannya.

Demikian pula para petani tanaman bawang merah yang mengalami berbagai permasalahan atau berbagai faktor diantaranya adalah teknik budidaya, kondisi lingkungan serta gangguan hama dan penyakit. 
Menurut Wibowo [1], dari ketiga faktor tersebut yang sampai sekarang menjadi masalah adalah gangguan hama dan penyakit. Salah satu teknik budidaya tanaman bawang merah adalah dengan monitoring secara rutin pada lahan penanaman bawang merah untuk mengetahui secara dini adanya gejala atau tanda penyakit pada tanaman bawang merah sehingga dapat dilakukan tindakan pengendalian agar penyakit tidak menyebar ke tanaman yang lain supaya hasil panen tetap optimal.

Namun dalam menentukan penyakit yang terdapat pada tanaman bawang merah ini masih menggunakan cara manual sehingga memerlukan proses yang lebih rumit dan memakan waktu yang cukup lama. Berdasarkan permasalahan tersebut, maka perlu kiranya dirancang suatu aplikasi yang mampu menganalisa suatu penyakit pada tanaman bawang merah secara cepat dan tepat.

Diagnosa terhadap hama dan penyakit pada tanaman bawang merah memang harus dilakukan secepat dan seakurat mungkin, dikarenakan hama dan penyakit pada tanaman tersebut dapat dengan cepat menyebar serta menyerang keseluruh lahan pertanian [1]. Dalam hal ini peran seorang expert sangat diandalkan untuk mendiagonosa dan menentukan jenis hama dan penyakit serta memberikan contoh cara penanggulangan guna mendapatkan solusi terbaik.

Namun demikian, keterbatasan yang dimiliki seorang expert terkadang menjadi kendala bagi para petani yang akan melakukan konsultasi guna menyelesaikan suatu permasalahan untuk mendapatkan solusi terbaik. Dalam hal ini sistem pakar dihadirkan sebagai alternatif kedua dalam memecahkan permasalahan setelah seorang expert.

Sistem pakar (expert system) merupakan suatu program komputer cerdas yang menggunakan knowledge (pengetahuan) dan prosedur inferensi untuk menyelesaikan masalah yang cukup sulit sehingga membutuhkan seorang ahli untuk menyelesaikannya [2].

Agar dapat memberikan solusi terhadap suatu permasalahan yang telah diuraikan tersebut maka dibutuhkan "Sistem Pakar Diagnosa Penyakit Tanaman Bawang Merah Menggunakan Metode Forward Chainning".

\section{STUDI PUSTAKA}

Studi pustaka adalah salah satu aktivitas untuk meninjau kembali literature yang telah dipublisasikan dari hasil penelitian yang serupa yang telah dibuat oleh bebrapa peneliti sebelumnya. Adapaun bebrapa studi pustaka yang digunakan dalam penelitian ini adalah sebagai berikut.
Penelitian mengenai sistem pakar diagonasa penyakit bawang oleh Wilda[3] dengan judul Sistem pakar diagnosa penyakit bawang merah menggunakan metode Certainty Factor. Dalam penelitian ini sistem pakar diagnosa penyakit bawang merah menggunakan metode Certainty Factor diujikan pada 2 knowledge engineer dan pakar, 90\% menyatakan sangat setuju, dan $10 \%$ setuju untuk interface dan akses sistem, sedangkan untuk fungsional sistem, $100 \%$ menyatakan sistem sudah berjalan baik. Keakuratan hasil diagnosa sistem dan uji laboratorium 78,5\%.

Peneltian juga dilakukan oleh fitriyah[4] dengan judul Sistem Pendeteksi Penyakit Daun Bawang Merah Probolinggo Menggunakan Metode Template Matching Berbasis Raspberry Pi”. Dimana metode yang diterapkan mampu berjalan dengan apa yang diinginkan terbukti dengan sistem dapat mengklasifikasikan jenis penyakit daun menjadi penyakit daun bercak ungu, embun bulu serta Moler.

Hal serupa juga dilakukan oleh Hidayat ${ }^{[5]}$ dengan judul Metode Forward Chaining Pada Sistem Pakar Untuk Diagnosa Hama dan Penyakit Padi. Penerapan metode inferensi forward chaining pada system pakar untuk diagnosa hama dan penyakit tanaman padi dapat menjadi informasi dan pengetahuan yang akan membantu masyarakat ataupun perorangan untuk mengetahui jenis hama dan penyakit apa yang menyerang tanaman padinya, tanpa harus menunggu dan mengharapkan jawaban langsung dari ahlinya

\section{METODE PENELITIAN}

Kegiatan yang dilakukan dalam penelitian adalah:

\section{A. Akuisisi Pengetahuan}

a. Studi literatur : mempelajari literature-literatur yang berhubungan dengan penelitian yang dilakukan yaitu Sistem Pakar dan Penyakit Bawang Merah. Literatur diperoleh dari berbagai sumber antara lain dari jurnal ilmiah, laporan penelitian, buku dan sumber lainnya yang memiliki hubungan dengan penelitian yang dilakukan.

b. Wawancara : wawancara dilakuakan dengang petani bawang merah yang berada di desa sembalun.

\section{B. Perancangan Sistem}

Focus pada desain sistem yang akan dibangun meliputi rancangan UML (Unified Modeling Language) yang terdiri dari : Use Case Diagram, Activity Diagram, rancangan basis data, rancangan antarmuka aplikasi. Adapun tahapan rancangan sistem sebagai berikut: 


\section{1) Use Case Diagram}

Perancangan awal dibuat kedalam bentuk use case diagram untuk menjelaskan gambaran sistem dan actor yang terlibat secara keseluruhan. Use case diagram sistem dapat di lihat pada Gambar 1.

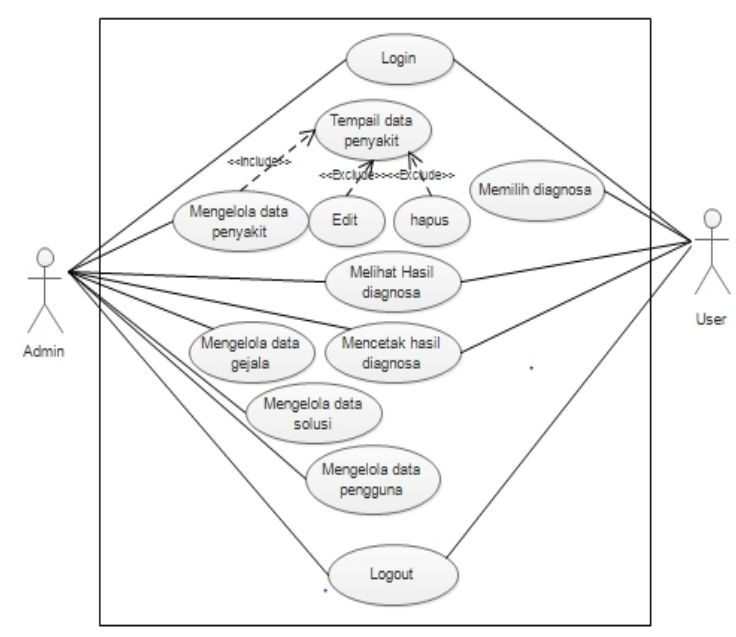

Gambar 1. Use Case Diagram

Dari usecase diatas dapat dilihat beberapa actor yang terlibat pada sitem informassi repository skripsi yaitu Admin, Mahasiswa dan User umum dimana masing - masing actor memiliki aktivitas sebagai berikut :

Admin dapat mengelola data skripsi,data mahasiswa, data pengguna dan data dosen, Kemudian Mahasiswa dapat mengupload file skripsi dan Visitor dapat melihat dan mencari judul skripsi serta download file skripsi.

\section{2) Activity Diagram}

Dalam perancangan sistem ini, penulis menggambarkan beberapa activity diagram yang ada pada perancangan sistem.

1. Activity diagram daftar penyakit

Aktifitas yang dilakukan menambah data penyakit, mengedit data penyakit, dan menghapus data penyakit.dapat dilihat pada gambar 2 .

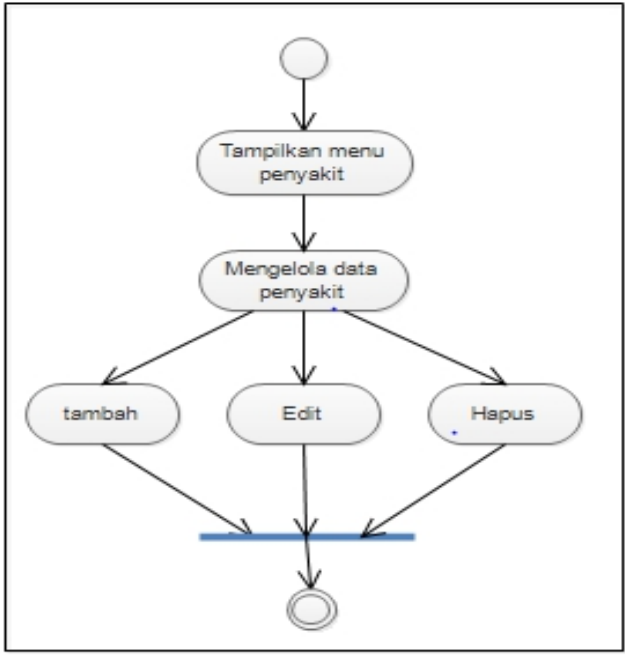

Gambar 2. Activity diagram daftar penyakit

2. Activity diagram Gejala

Pada Activity Diagram Gejala ini akan menjelaskan tentang proses pengolahan data geala yang dilakukan oleh admin/pakar dapat dilihat pada gambar 3 .

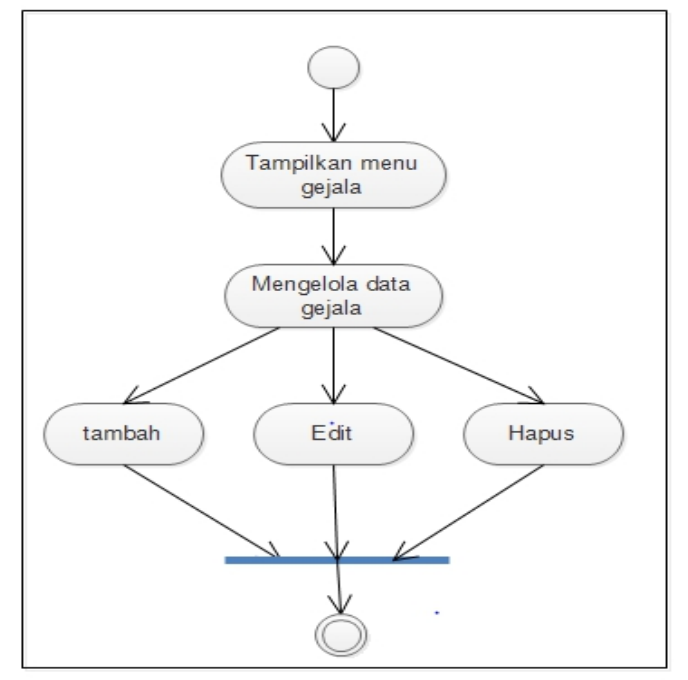

Gambar 3. Activity Diagram Gejala

3. Activity Diagram Hasil Diagnosa

Pada activity diagran hasil diagnosa ini, proses yang dilakukan memilih diagnosa, melihat hasil diagnosa dan mencetak hasil diagnosa dapat dlihat pada gamabr 4 . 


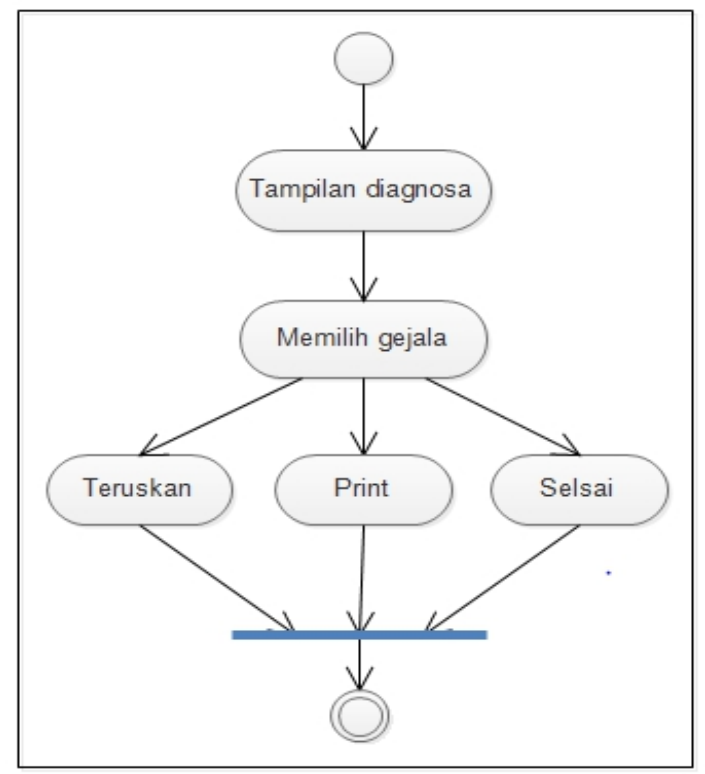

Gambar 4. Activity Diagram Hasil Diagnosa

\section{2) Class Diagram}

Class Diagram digunakan menampilkan beberapa kelas serta paket yang ada dalam system/perangkat lunak. Class Diagram sistem pakar diagnose penyakit bawang merah dapat dilihat pada gambar 5 .

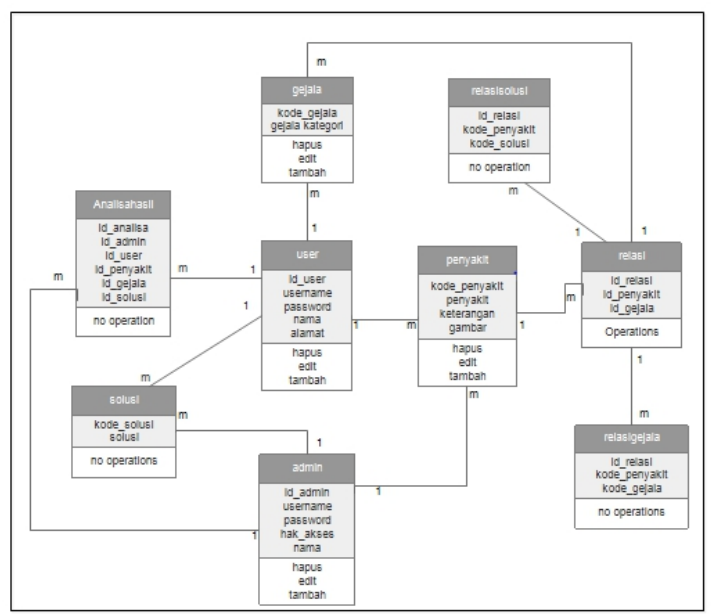

Gambar 5. Class diagram sistem pakar diagnose penyakit bawang merah

\section{Implementasi}

Pada tahapan ini deskripsi perancangan diterjemahkan menggunakan visual studio code.

\section{Pengujian}

Pada tahap ini pengujian terhadap sistem yang telah dikembangkan dengan cara memasukan gejala-gejala yang ada penyakit bawang merah dan juga solusi penanganan penyakit.

\section{HASIL DAN PEMBAHASAN}

Adapun tampilan program yang dibuat oleh peneliti pada program aplikasi sistem pakar untuk mendiagnosa penyakit bawang merah menggunakan metode forward chining sebagai berikut:

\section{A. Tampilan Halaman Login User}

Pada tampilan halaman menu login ini disediakan untuk user yang sudah terdaftar oleh admin. Apabiala user memilih login maka akan muncul halaman login untuk masuk ke menu utama login seperti terlihat pada gambar 6 .

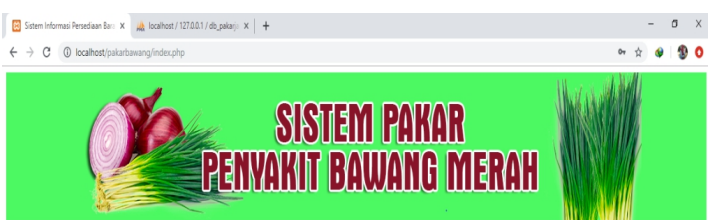

Gambar 6. Tampilan Halaman Login User

\section{B. Tampilan Halaman Utama User}

Pada halaman ini ditampilkan beberapa menu diantaranya adalah menu home, menu diagnosa, menu data diagnosa, menu bantuan, menu pengguna atau profil, menu logut. Pada tampilan menu utama ini pengguna bisa langsung login terlebih dahulu dan melakaukan konsultasi seperti terlihat pada gambar 7 .
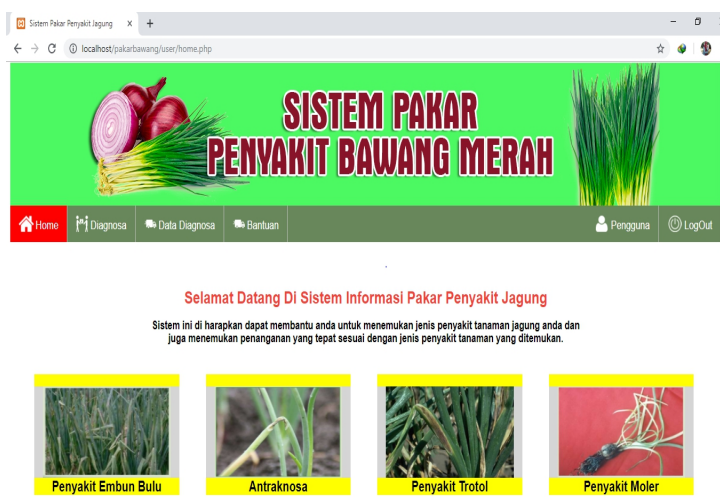

Gambar 7. Tampilan Halaman Utama User

\section{Tampilan Halaman Diagnosa}

Tampilan halaman diagnosa merupakan proses dari mendiagnosa penyakit bawang merah yang dilakukan oleh user seperti terlihat pada gambar 8 . 

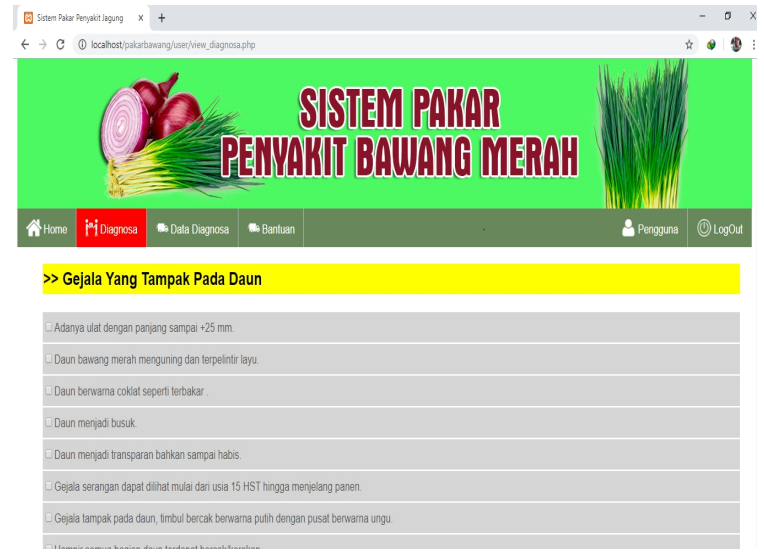

Gambar 8. Tampilan Halaman Diagnosa

\section{Tampilan Hasil Analisa}

Tampilan hasil analisa akan muncul apabila pengguna sudah menjawab pertanyaan konusltasi dan sudah memenuhi gejala penyakit seperti terlihat pada gambar 9 .

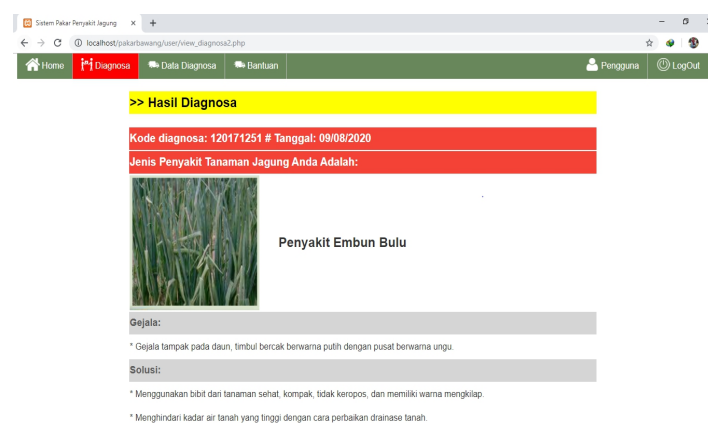

Gambar 9. Tampilan Hasil Analisa

\section{E. Tampilan Halaman Data Diagnosa}

Tampilan halaman data diagnosa disediakan untuk melihat hasil-hasil diagnosa yang telah dilakukan, user juga bisa mencetak hasil diagnosa sehingga mempermudah mengambil laporan hasil diagnosa. seperti terlihat pada gambar 10 .

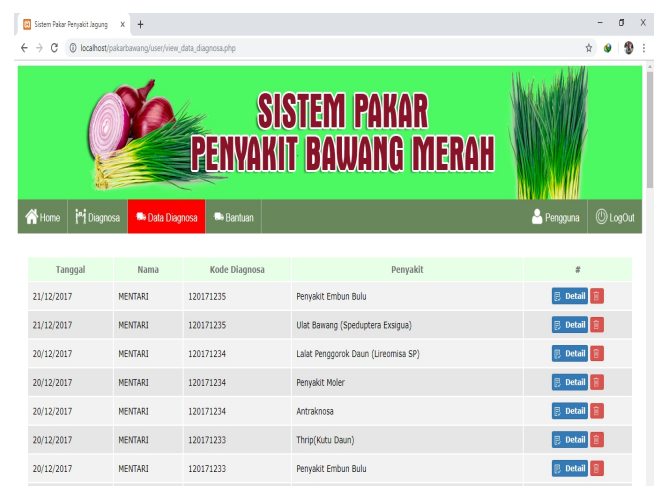

Gambar 10. Tampilan Halaman Data Diagnosa

\section{F. Tampilan Halaman Profil}

Pada halaman profil ini disedikan untuk mengubah atau mengganti username maupun password pengguna, yang sebelumnya telah dibuatkan oleh admin seperti terlihat pada gambar 11 .

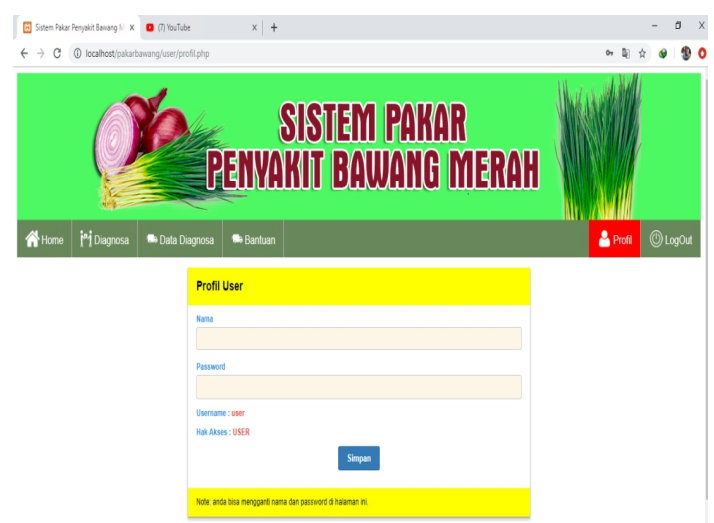

Gambar 11. Tampilan Halaman Profil

\section{G. Tampilan Halaman Utama Admin}

Halaman ini disediakan khusus untuk admin/pakar untuk mengolah data, yakni tambah, ubah dan hapus data serta membuat relasi aturan. Pada halaman ini disediakan beberapa menu diantaranya menu home, menu penyakit, menu solusi, menu penggun, menu laporan dan menu profil seperti terlihat pada gambar 12 .

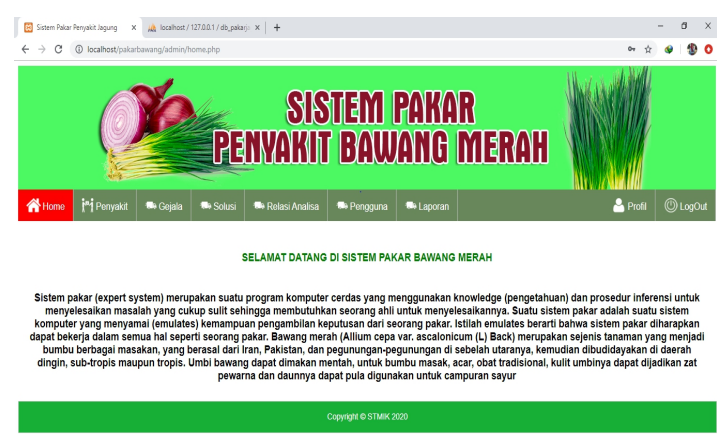

Gambar 12. Tampilan Halaman Utama Admin

\section{H. Halaman Tambah Penyakit}

Halaman tambah penyakit menyediakn menu untuk admin/pakar yang digunakan untuk menambah data penyakit seperti terlihat pada gambar 13 . 

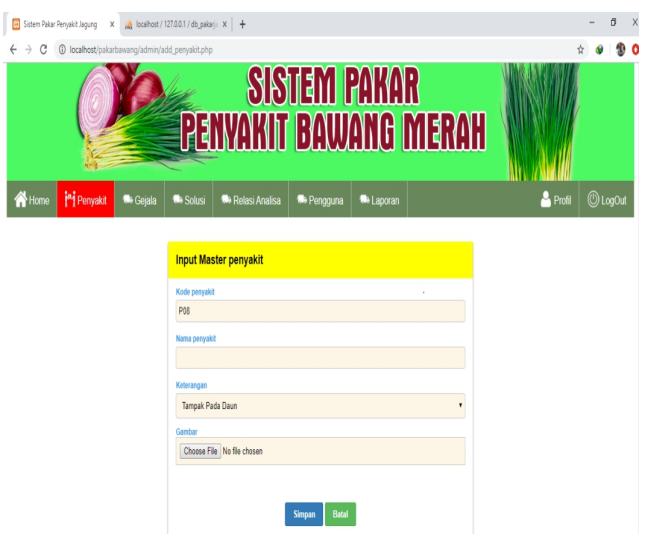

Gambar 13. Halaman Tambah Penyakit

\section{Halaman Data Gejala}

Halaman data gejala menyediakan menu untuk mengubah dan menghapus data penyakit seperti terlihat pada gambar 14 .

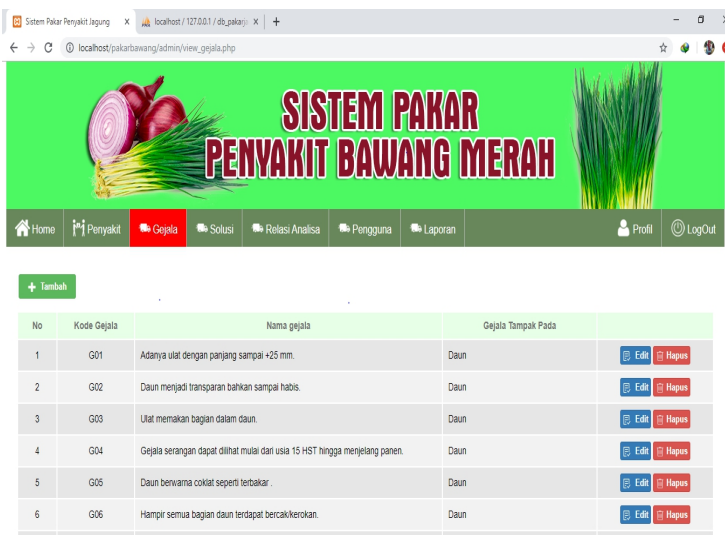

Gambar 14. Halaman data Gejala

\section{J. Halaman Data Solusi}

Halaman data solusi menyediakan menambah dan menghapus nama penyakit, definisi penyakit serta solusi dan pengobatan seperti terlihat pada gambar 15 .

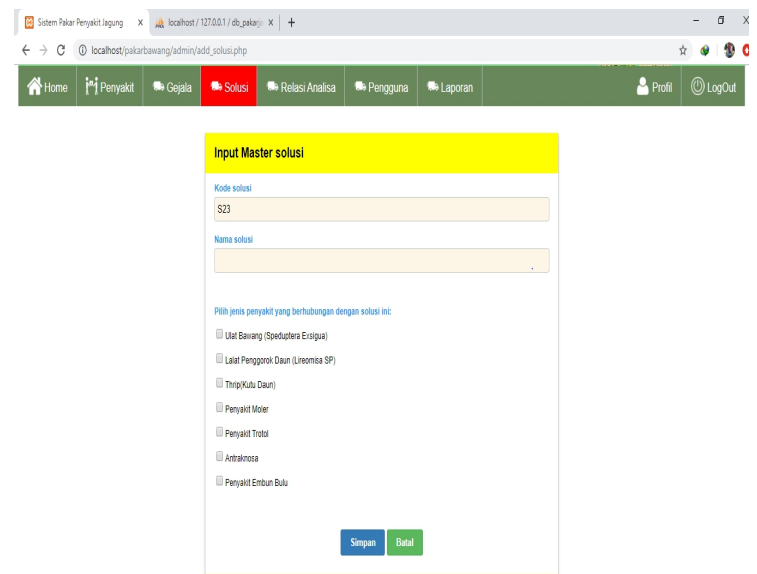

Gambar 15. Tampilan Input data Pengguna

\section{K. Halaman Relasi Analisa}

Halaman relasi analisa menyediakan tampilan menu penyakit,menu gejala dan menu solusi seperti terlihat pada gambar 16
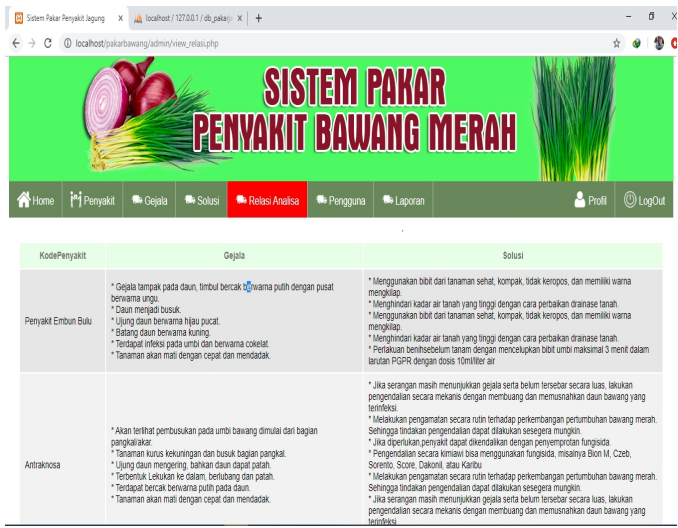

Gambar 16. Halaman Relasi Analisa

\section{Halaman Laporan}

Halaman laporan ini menyedikakan data-data pengguna yang telah melakukan konsultasi. Data yang disediakan tanggal konsultasi, user dan hasil konsultasi seperti terlihat pada gambar 17 .
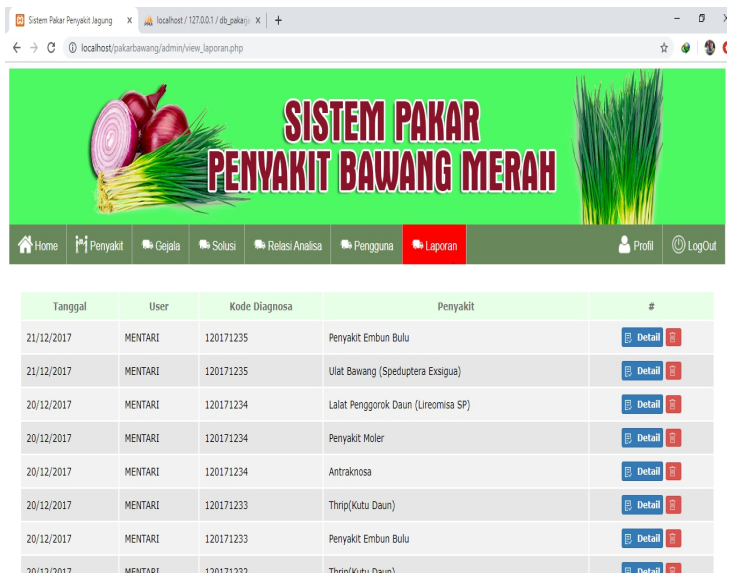

Gambar 17. Halaman Laporan

\section{KESIMPULAN}

Berdasarkan pengembangan yang telah dilakukan selama proses perancangan hingga implementasi sistem pakar diagnosa penyakit tanaman bawang merah menggunakan metode forward chining maka dapat diambil kesimpulan sebagai berikut:

Sistem Pakar Diagnosa Penyakit Tanaman Bawang Merah mampu menyediakan konsultasi antara pengguna dengan sistem serta memberikan hasil diagnosa yang berupa solusi serta penanganan penyakit yang telah didiagnosa tersebut 


\section{UCAPAN TERIMKASIH}

Peneliti mengucapkan terimakasih sebesar-besarnya kepada STMIK Syaikh Zainuddin NW Anjani dan semua pihak yang terlibat dalam penelitian ini sehingga penelitian ini dapat dipublikasikan.

\section{DAFTAR PUSTAKA}

[1] Wibowo, Singgih. 1989. Budidaya Bawang Putih, Bawang Merah dan Bawang Bombay. Penebar Swadaya. Jakarta.

[2] Feigenbaum, E.A, \& Buchanan B.G., DENDRAL and Meta-DENDRAL: roots of knowledge systems and expert systems applications. Artificial Intellegence. 1993

[3] Maulana, R. Dkk Sistem Pendeteksi Penyakit Daun Bawang Merah Probolinggo Menggunakan Metode Template Matching Berbasis Raspberry Pi. Jurnal Pengembangan Teknologi Informasi dan Ilmu Komputer, vol. 2, no. 12, p. 6026-6031, agu. 2018. ISSN 2548-964X.

[4] Wilda, Nurul. (2017). Sistem Pakar Diagnosa Penyakit Tanaman Bawang Merah Menggunakan Metode Certainty Factor. Jawa Timur: UNISK

[5] Suhendri, dkk. (2017) Merancang Sistem Pakar Diagnosa Penyakit Tanaman Mangga dengan Algoritma Depth First Search Berbasis Mobile : Universitas Manjalengk. ISBN 978-602-8557-20-7 